\title{
The concentration of hydrogen peroxide in exhaled air depends on expiratory flow rate
}

\author{
M.B. Schleiss, O. Holz, M. Behnke, K. Richter, H. Magnussen, R.A. Jörres
}

The concentration of hydrogen peroxide in exhaled air depends on expiratory flow rate. M.B. Schleiss, O. Holz, M. Behnke, K. Richter, H. Magnussen, R.A. Jörres. C) ERS Journals Ltd 2000.

ABSTRACT: Hydrogen peroxide $\left(\mathrm{H}_{2} \mathrm{O}_{2}\right)$ is known to be detectable in exhaled air. The present study aimed to determine whether the concentration of exhaled $\mathrm{H}_{2} \mathrm{O}_{2}$ depends on expiratory flow rate in order to make inferences on the site of its production within the lung.

Breath condensate was collected in cooled Teflon tubes, at three different expiratory flow rates, in 15 healthy or mild asthmatic subjects. Tests were repeated 2-5 times to assess reproducibility.

Mean \pm SEM concentrations of $\mathrm{H}_{2} \mathrm{O}_{2}$ at flow rates of 140,69 and $48 \mathrm{~mL} \cdot \mathrm{s}^{-1}$ were $0.12 \pm$ $0.02,0.19 \pm 0.02$ and $0.32 \pm 0.03 \mu \mathrm{M}$, respectively. These values differed significantly from each other $(p<0.001)$. For comparison, average coefficients of variability within repeated measurements at each of the three flow rates were 68,62 and $82 \%$, respectively.

These data demonstrate that the concentration of exhaled hydrogen peroxide depends on expiratory flow rate. Since flow dependence is an indicator of production within the airways, this result suggests that, to a large extent, the exhaled hydrogen peroxide originates within the airways. However, even under strictly controlled conditions, a high degree of variability persists, which may limit the usefulness of exhaled hydrogen peroxide as a marker of airway inflammation.

Eur Respir J 2000; 16: 1115-1118.
Hospital Grosshansdorff, Centre for Pneumology and Thoracic Surgery, Research Laboratory, D-22927 Grosshansdorf, Germany.

Correspondence: O. Holz, Forschungslabor, Krankenhaus Grosshansdorf, Zentrum für Pneumologie und Thoraxchirurgie, D-22927 Grosshansdorf, Federal Republic of Germany. Fax: 49 4102692295

Keywords: Exhaled air expiratory flow rate hydrogen peroxide reproducibility

Received: September 301999 Accepted after revision June 12000

This study was supported by the LVA, Freie und Hansestadt Hamburg, Germany.
Hydrogen peroxide $\left(\mathrm{H}_{2} \mathrm{O}_{2}\right)$ in exhaled air has been proposed as a potential noninvasive marker of airway inflammation. Several groups have explored its value in different groups of subjects such as smokers or patients with asthma, chronic obstructive pulmonary disease (COPD), bronchiectasis or cystic fibrosis [1-6]. In contrast to exhaled nitric dxide (NO), the exhaled $\mathrm{H}_{2} \mathrm{O}_{2}$ is also elevated in patients with COPD [4], suggesting that it might provide independent and valuable information. The exhaled $\mathrm{H}_{2} \mathrm{O}_{2}$ is likely to originate from inflammatory cells within the lung or airways, such as macrophages, neutrophils and eosinophils, whereby differences in number and activation of these cells could explain its relationship to disease activity [4]. However, irrespective of which cells produce the exhaled $\mathrm{H}_{2} \mathrm{O}_{2}$, the basic question arises as to whether it is primarily derived from the bronchial or the alveolar region. This question cannot be answered a priori, since cells capable of $\mathrm{H}_{2} \mathrm{O}_{2}$ production reside in both regions of the lung. It may be answered, however, through a type of reasoning and experiment analogous to that which has been successfully applied in the analysis of exhaled NO [7-9].

Accordingly, the present approach was based on predictions derived from a simplified lung model. When the bronchi are lumped into a tube of finite length, their contribution to the exhaled $\mathrm{H}_{2} \mathrm{O}_{2}$ should be flowdependent, because the time available to accumulate $\mathrm{H}_{2} \mathrm{O}_{2}$ from the airway walls would be inversely propor- tional to flow rate. In contrast, flow velocity plays only a minor role in the lung periphery, and thus the alveolar contribution to the exhaled $\mathrm{H}_{2} \mathrm{O}_{2}$ should not depend on expiratory flow rate. Therefore, the detection of flow dependence would indicate that the exhaled $\mathrm{H}_{2} \mathrm{O}_{2}$ arises at least partially from the airways.

Based on these considerations, the effects of flow rate on exhaled $\mathrm{H}_{2} \mathrm{O}_{2}$ levels were studied in healthy and mild asthmatic subjects in order to infer its origin within the lung. Tests were performed repeatedly to compare the magnitude of flow-dependence with the variability of measurements.

\section{Methods}

\section{Theoretical background}

For analysis, a simplified model of the lung was used, wherein the alveolar region is identified with a peripheral compartment and the bronchial region with a central compartment, both connected to each other. The reasoning is based on the fact that the kinetics of gas transport differ between both compartments, owing to the differences in geometry.

The central compartment can be represented by a single tube, with the consequence that the transit time of air streaming through the tube is inversely proportional to its 
flow rate. If $\mathrm{H}_{2} \mathrm{O}_{2}$ would be produced solely in the lung periphery, the central airways would act solely as a volume that has to be crossed. They would delay the appearance of the peripherally produced $\mathrm{H}_{2} \mathrm{O}_{2}$ at the mouth but would not alter its concentration. Conversely, if $\mathrm{H}_{2} \mathrm{O}_{2}$ would be produced solely in the central compartment, its concentration in exhaled air should decrease with increasing flow rate, because transit time, i.e., the time available to accumulate $\mathrm{H}_{2} \mathrm{O}_{2}$ from the airway wall, decreases. In particular, the concentration of $\mathrm{H}_{2} \mathrm{O}_{2}$ should approach zero at high expiratory flow rates.

In practice, however, the concentration of $\mathrm{H}_{2} \mathrm{O}_{2}$ as a function of flow rate may not necessarily be either constant or inversely proportional to flow rate. It could be inbetween owing to two reasons: firstly, the flux of $\mathrm{H}_{2} \mathrm{O}_{2}$ from the airway wall into the lumen is likely to follow the concentration gradient; therefore, it will be lower at lower flow rates, when the back pressure in the lumen rises; secondly, if there should be some contribution from the lung periphery, the level of the curve would be elevated. This would be reflected by the concentration at high flow rates not approaching zero, but approaching the concentration that is maintained in the lung periphery instead. These considerations demonstrate that the flow dependence of exhaled $\mathrm{H}_{2} \mathrm{O}_{2}$ provides a clue as to whether the exhaled $\mathrm{H}_{2} \mathrm{O}_{2}$ arises from central or peripheral locations within the lung, and to which extent.

\section{Subjects}

Fifteen nonsmoking subjects participated in this study, among them eight healthy subjects (four male, four female; mean \pm SD) age, $31 \pm 7$ yrs; forced expiratory volume in one second (FEV1), $100.6 \pm 10.1 \%$ of predicted (\% pred) [10]), four subjects with a clinical history of mild asthma (four male; age, 36 \pm 10 yrs; FEV1, $94.0 \pm 6.9 \%$ pred) and three subjects with allergic rhinitis (one male, three female; age, $29 \pm 2$ yrs; FEV1, $120.5 \pm 6.3 \%$ pred). None of the subjects used inhaled corticosteroids; the (occasional) inhalation of $\beta_{2}$-adrenoceptor agonists was stopped at least $6 \mathrm{~h}$ before each test and subjects did not have symptoms of a respiratory tract infection, 4 weeks before the tests.

\section{Experimental set-up}

Subjects exhaled through three different resistors made from copper and stainless steel into cooled (mean $\pm \mathrm{SD}$ ) temperature, $-13.6 \pm 1.3^{\circ} \mathrm{C}$ ) Teflon tubes with an inner diameter of $10 \mathrm{~mm}$ and a length of $40 \mathrm{~cm}$. Throughout each exhalation, they kept a constant pressure of 20 mbar over ambient pressure to induce closure of the vellum. Pressure was measured by an electronic pressure gauge (Greisinger, Regenstauf, Germany) and was displayed for control. At a pressure difference of 20 mbar, the three resistors, which were inserted into the mouthpiece in random order, corresponded to flow rates of 140,69, and $48 \mathrm{~mL} \cdot \mathrm{s}^{-1}$. Each test comprised of 21 expirations with a duration of $20 \mathrm{~s}$ for each flow rate, resulting in total exhaled volumes of 20.1, 29.0, and 58.8 L air. This procedure was chosen to ensure that flow dependence was assessed correctly and also that volumes of condensate were sufficient for analysis at all flow rates. To assess intraindividual variability, each subject performed $2-5(2: n=3$;
$3: \mathrm{n}=1 ; 4: \mathrm{n}=10 ; 5: \mathrm{n}=1$ ) tests on different days (median 7; range $1-40$ days).

\section{Analysis of hydrogen peroxide}

Immediately after collection, the volume of the condensate was determined, and an aliquot was taken for the $\mathrm{H}_{2} \mathrm{O}_{2}$ analysis. Horseradish peroxidase (final concentration: 1 $\mu \mathrm{g} \cdot \mathrm{mL}^{-1}$; Boehringer, Mannheim, Germany) and $p$-hydroxyphenyllactic (PHPL) acid (0.04 mM; Sigma, München, Germany) were added $[2,11]$. After mixing, samples were stored at $-20^{\circ} \mathrm{C}$ until fluorometric analysis (LS 50, PerkinElmer, Norwalk, USA; excitation wavelength $295 \mathrm{~nm}$, emission wavelength $405 \mathrm{~nm}$ ). One standard curve was used to calculate the $\mathrm{H}_{2} \mathrm{O}_{2}$ concentration in all the samples.

\section{Statistical analysis}

Arithmetic mean values and standard errors of mean \pm SEM were computed for $\mathrm{H}_{2} \mathrm{O}_{2}$ concentrations and the volumes of condensate. Median values and ranges were derived for per cent differences between flow rates and for coefficients of variation. Comparisons between flow rates were performed by paired t-tests using the individual mean values. Two-tailed tests were performed and the level of statistical significance was assigned at $\mathrm{p}=0.05$.

\section{Results}

The mean \pm SEM volume of condensate obtained was $660 \pm 9,445 \pm 7$, and $304 \pm 10 \mu \mathrm{L}$ at flow rates of 140,69 , and $48 \mathrm{~mL} \cdot \mathrm{s}^{-1}$, respectively. $\mathrm{H}_{2} \mathrm{O}_{2}$ concentrations were more or less flow-dependent in each subject, and for the whole group concentrations differed significantly between flow rates ( $p<0.001$, each comparison). Mean \pm SEM concentrations of $\mathrm{H}_{2} \mathrm{O}_{2}$ as averaged over all subjects were $0.125 \pm 0.016,0.193 \pm 0.021$, and $0.319 \pm 0.030 \mu \mathrm{M}$, respectively (fig. 1). The values did not depend on the order in which the measurements were taken.

Geometric mean values (range) of the individual coefficients of variation within repeated measurements were 68 (28-193), 62 (5-227) and 82 (17-930) \% at flow rates of 140,69 and $48 \mathrm{~mL} \cdot \mathrm{s}^{-1}$, respectively. To compare

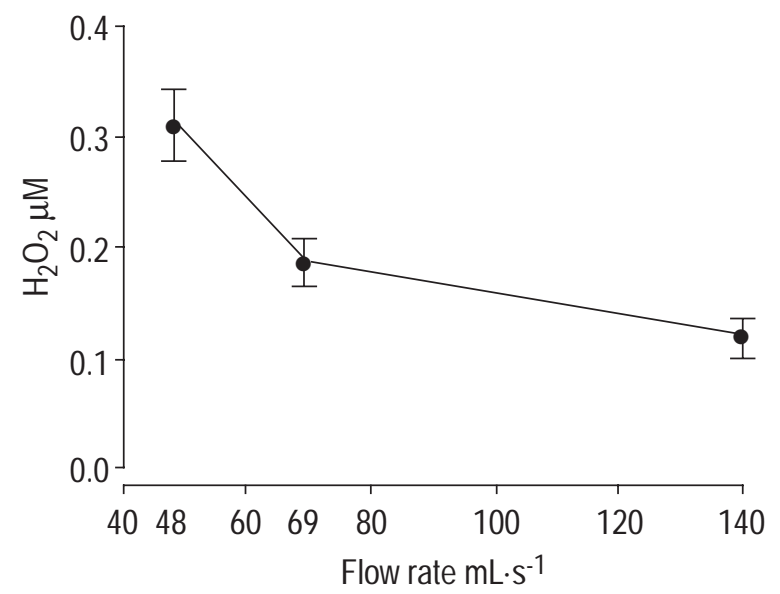

Fig. 1. - Overall mean \pm SEM of exhaled hydrogen peroxide $\left(\mathrm{H}_{2} \mathrm{O}_{2}\right)$ at three different expiratory flow rates. These values were derived from the individual mean values per flow rate. 
the intra-individual variations with the magnitude of flow dependence, the per cent differences between values obtained at the three flow rates relative to either the lower or higher of both flow rates were computed. Relative to the higher flow rate, geometric mean (range) changes were 44 (22-82) \% between 48 and $69 \mathrm{~mL} \cdot \mathrm{s}^{-1}, 61(19-159) \%$ between 69 and $140 \mathrm{~mL} \cdot \mathrm{s}^{-1}$, and $136(72-324) \%$ between 48 and $140 \mathrm{~mL} \cdot \mathrm{s}^{-1}$. Relative to the lower flow rate, corresponding changes were 30 (18-45), 36 (16-61) and 57 (42-76) \% respectively.

\section{Discussion}

The present study revealed that the level of exhaled $\mathrm{H}_{2} \mathrm{O}_{2}$ significantly depends on expiratory flow rate, indicating that the exhaled $\mathrm{H}_{2} \mathrm{O}_{2}$ is at least partially produced within the airways. Flow dependence was observed in all the individuals, although it showed large differences in magnitude. Despite strict control of expiratory flow rates, considerable variability remained when measurements were repeated on different days.

The type of reasoning which the analysis was based on, was the same as that applicable to the analysis of exhaled NO. NO measurements even allow for the derivation of an effective bronchial mucosal NO concentration and a corresponding bronchial transfer factor, which describes its transport across airway walls, as well as a peripheral NO concentration that is fed into the bronchial tube upon expiration [7]. This type of model exists in different, similar or equivalent versions $[8,9,12]$ and detailed mathematical expressions have been derived that relate measured concentrations to the parameters of the models. Due to the scatter of the data and the fact that measurements could only be taken at three different flow rates, it is numerically questionable to apply such a model to the $\mathrm{H}_{2} \mathrm{O}_{2}$ data, since the parameter estimates will probably not be very reliable. However, when this was tried, the computational procedure converged in all subjects, with a median (interquartiles) peripheral $\mathrm{H}_{2} \mathrm{O}_{2}$ concentration of$0.05(-0.11-0.02) \mu \mathrm{M}$ and a bronchial mucosal concentration of $2.85(1.63-3.52) \mu \mathrm{M}$. As the peripheral $\mathrm{H}_{2} \mathrm{O}_{2}$ concentration has to be non-negative, this suggested that in the data, the alveolar contribution to the exhaled $\mathrm{H}_{2} \mathrm{O}_{2}$ was negligible as compared to the bronchial contribution. This is true, despite the observation that with flow rates towards infinity, some of the $\mathrm{H}_{2} \mathrm{O}_{2}$ curves appeared to settle down at values markedly larger than zero.

The authors took care to standardize not only expiratory flow rates but also the time of expiration. Theoretically, $\mathrm{H}_{2} \mathrm{O}_{2}$ levels within the alveoli could increase over time. Therefore, with a fixed volume of air collected, $\mathrm{H}_{2} \mathrm{O}_{2}$ levels could increase at lower flow rates, simply due to the fact that a longer period of time is needed for expiration. This implies that sampling, as represented by the breath condensate, is performed over a longer period of time. Such a process could simulate a flow dependence of exhaled $\mathrm{H}_{2} \mathrm{O}_{2}$ through a time-dependence. In order to exclude this false inference, the time of expiration was fixed to $20 \mathrm{~s}$ at all flow rates. This, however, resulted in different total volumes of air being sampled by the freezing device, and concomitantly a relatively higher contribution of air from the bronchi to total volume at lower flow rates. It must be noted, however, that this type of potential bias would also have been in favour of a predominantly bronchial $\mathrm{H}_{2} \mathrm{O}_{2}$ production. When the volume of air exhaled through the sampling device was compared with the volume of condensate, there were no large deviations from proportionality, indicating that the sampling of breath condensate was similarly efficient at all flow rates. Although the requirement of a constant time of expiration limited the range of flow rates applicable, flow dependence was quite obvious in the data.

When measurements were repeated on different days, a high degree of variability emerged despite the strict standardization of flow rates. Average coefficients of variation at different flow rates were in the same range as average per cent changes from one flow rate to the other. Therefore, it seems that significant sources of variability, of either methodological or biological origin, remained. This fact, in combination with the time needed for analysis, does not favour the measurement of exhaled $\mathrm{H}_{2} \mathrm{O}_{2}$ as compared, e.g., to that of exhaled NO. However, the ongoing interest in noninvasive markers of airway inflammation and in particular the demand to monitor patients with COPD, may argue in favour of exhaled $\mathrm{H}_{2} \mathrm{O}_{2}$ despite the difficulties that have been addressed.

The flow rates used in the present study were lower than the average flow rates achieved during normal tidal breathing, which is usually chosen to collect the breath condensate. Due to the flatness of the curve at higher flow rates, it is unlikely that flow dependence has markedly biased the results of the previous studies or was the major source of the variability observed. It could be argued, however, that the use of lower, well standardized flow rates during collection would result in higher concentrations of $\mathrm{H}_{2} \mathrm{O}_{2}$, and therefore, in a lower number of measurements that fall below the detection limit.

The authors found no significantly elevated levels of exhaled $\mathrm{H}_{2} \mathrm{O}_{2}$ in the subjects with asthma, as compared to the healthy controls. It has to be noted, however, that the subjects only had very mild disease with an occasional use of bronchodilators as their only therapy. Therefore, the present findings do not contradict previous reports on elevated concentrations of exhaled $\mathrm{H}_{2} \mathrm{O}_{2}$ in asthma [2, 3], especially in view of the large scatter within the reported data.

Since the conclusion that the exhaled $\mathrm{H}_{2} \mathrm{O}_{2}$ at least partially originates within the airways resides on indirect evidence, it could be argued that it critically depends on the model used or the appropriateness of the model. It might appear that our argument is circular as it seems to be based on the a priori assumption that the alveolar $\mathrm{H}_{2} \mathrm{O}_{2}$ concentration is low. However, this is one of the conclusions. The increase in $\mathrm{H}_{2} \mathrm{O}_{2}$ levels, with decreasing flow rates, unequivocally demonstrates that the bronchial contribution to the exhaled $\mathrm{H}_{2} \mathrm{O}_{2}$ is large as compared to the alveolar contribution. It is difficult to see how this phenomenon could be explained by other plausible mechanisms which do not rely on artificial ad hoc assumptions. Furthermore, if alveolar $\mathrm{H}_{2} \mathrm{O}_{2}$ levels were high, $\mathrm{H}_{2} \mathrm{O}_{2}$ could be absorbed within the bronchi during expiration and consequently the level of exhaled $\mathrm{H}_{2} \mathrm{O}_{2}$ would have to fall with decreasing flow rate, in contrast to what was observed in the present study. Therefore, within the range of applicability of the very general model used, the conclusions appear to be valid. 
The model per se could be a matter of debate, especially the fact that the airways are thought to be combined into a single tube. This assumption, however, is not critical as long as the majority of airways are acting in parallel in such a way that the average residence or transit time of air is inversely related to flow rate. Noteworthy enough, in the case of exhaled NO which is predominantly produced within the central airways, the validity of the analogous model can be directly demonstrated through the peculiar time course of the exhaled NO signal after a sudden change in expiratory flow rate [13]. Taken together, these considerations indicate that the concepts underlying the study are sound, and that the interpretation of the data is justified.

To conclude, the study shows that the hydrogen peroxide concentration in exhaled air depends on expiratory flow rate. This suggests that the exhaled hydrogen peroxide is at least partially produced within the airways. However, even under strict control of flow rates, considerable variability remains which may limit the usefulness of exhaled hydrogen peroxide as a noninvasive marker of airway inflammation.

\footnotetext{
Acknowledgements. The authors gratefully acknowledge the help of the subjects who participated in this study.
}

\section{References}

1. Nowak D, Kasielski M, Pietras T, Bialasiewicz P, Antczak A. Cigarette smoking does not increase hydrogen peroxide levels in expired breath condensate of patients with stable COPD. Monaldi Arch Chest Dis 1998; 53: 268-273.

2. Jöbsis Q, Raatgeep HC, Hermans PW, de Jongste JC. Hydrogen peroxide in exhaled air is increased in stable asthmatic children. Eur Respir J 1997; 10: 519-521.

3. Horvath I, Donnelly LE, Kiss A, et al. Combined use of exhaled hydrogen peroxide and nitric oxide in monitoring asthma. Am J Respir Crit Care Med 1998; 158: 10421046.

4. Dekhuijzen PN, Aben KK, Dekker I, et al. Increased exhalation of hydrogen peroxide in patients with stable and unstable chronic obstructive pulmonary disease. $A m J$ Respir Crit Care Med 1996; 154: 813-816.

5. Loukides S, Horvath I, Wodehouse T, Cole PJ, Barnes PJ. Elevated levels of expired breath hydrogen peroxide in bronchiectasis. Am J Respir Crit Care Med 1998; 158: 991-994.

6. Worlitzsch D, Herberth G, Ulrich M, Doring G. Catalase, myeloperoxidase and hydrogen peroxide in cystic fibrosis. Eur Respir J 1998; 11: 377-383.

7. Kirsten AM, Jörres RA, Kirsten D, Magnussen $H$. Determination of bronchial nitric oxide (NO) concentrations in subjects with mild asthma and healthy subjects. Am J Respir Crit Care Med 1997; 155: A825.

8. Tsoukias NM, George SC. A two-compartment model of pulmonary nitric oxide exchange dynamics. $J \mathrm{Appl}$ Physiol 1998; 85: 653-666.

9. Silkoff PE, Sylvester JT, Zamel N, Permutt S. Mechanism of elevated exhaled NO concentration in asthma. Am J Respir Crit Care Med 1999; 159: A409.

10. Quanjer PH, Tammeling GJ, Cotes JE, Pedersen OF, Peslin R, Yernault JC. Lung volumes and forced ventilatory flows. Report Working Party Standardization of Lung Function Tests, European Community for Steel and Coal. Official Statement of the European Respiratory Society. Eur Respir J Suppl 1993; 16: 5-40.

11. Hyslop PA, Sklar LA. A quantitative fluorimetric assay for the determination of oxidant production by polymorphonuclear leukocytes: its use in the simultaneous fluorimetric assay of cellular activation processes. Anal Biochem 1984; 141: 280-286.

12. Pietropaoli AP, Perillo IB, Torres A, et al. Simultaneous measurement of nitric oxide production by conducting and alveolar airways of humans. $J$ Appl Physiol 1999; 87: 1532-1542.

13. Jörres RA, Sonnemann H, Lohmann J, Magnussen H. Determination of bronchial production characteristics of exhaled nitric oxide (NO) in human subjects. Am J Respir Crit Care Med 1998; 157: A612. 